EESTI NSV TEADUSTE AKADEEMIA TOIMETISED. 30. KÖIDE

FOOSIKA * MATEMAATIKA. 1981, NR. 2

ИЗВЕСТИЯ АКАДЕМИИ НАУК ЭСТОНСКОИ ССР. ТОМ 30 ФИЗИКА * МАТЕМАТИКА. 1981, № 2

В. БОГОМОЛОВ, Ю. КУМЗЕРОВ, В. ПИМЕНОВ

удК $537.312 .62: 536.74$

\title{
ИЗМЕРЕНИЕ ТЕПЛОЕМКОСТИ ТОНКИХ МЕТАЛЛИЧЕСКИХ НИТЕЙ В ОБЛАСТИ СВЕРХПРОВОДЯЩЕГО ПЕРЕХОДА
}

V. BOGOMOLOV, J. KUMZEROV, V. PIMENOV. PEENTE METALLNIITIDE SOOJUSMAHTUVUSE MOOTMINE OLIJUHTIVA SIIRDE PIIRKONNAS

V. BOGOMOLOV, Y. KUMZEROV, V. PIMENOV. MEASURING THE HEAT CAPACITY OF FINE METAL FILAMENTS IN THE FIELD (REGION) OF SUPERCONDUCTIVE TRANSITION

\section{(Представил Э. Липпмаа)}

Физические свойства металлов в мелкодисперсном состоянии, в том числе тонких металлических пленок и нитей, в настоящее время интенсивно изучаются. Теплоемкость является важной характеристикой таких объектов, особенно в области фазовых переходов, где проявляются ее особенности. Однако измерения ее обычными калориметрическими методами весьма затруднительны из-за малых объемов исследуемых образцов. Поэтому при измеренин теплоемкости тонких металлических пленок используют неравновесные методы [ ${ }^{1}$ ]. В данной работе описан неравновесный метод измерения теплоемкости ультратонких металлических нитей в области сверхпроводящего перехода при подогреве образца током с разделением частот полезного сигнала и нагревателя.

Металлические нити $\mathrm{Hg}, \mathrm{Ga}, \mathrm{In}, \mathrm{Sn}$ диаметрами от 20 до 100 А̊ получались вдавливанием жидкого металла в каналы природного хризотилового асбеста $\left[{ }^{2}\right]$. Образцы представляли собой пучки асбестовых волокон диаметром в несколько десятых долей $м м$, длиной $\sim 1$ см и содержали около $10^{6}$ параллельных металлических нитей со средним расстоянием между ними $\sim 200 \AA \AA$. На пучок волокон наматывалась манганиновая проволока с сопротивлением в несколько $O_{M}$ (см. рис. 1).

Теплоемкость измерялась следующим образом. На нагреватель 4 (рис. 1) подавался сигнал с частотой $v$. Переменный тепловой поток удвоенной частоты $2 v$, затухая, доходил до нитей и вызывал колебания их температуры, обратно пропорциональные теплоемкости нитей. Выражение для теплоемкости имеет вид

$$
C(T)=Q / 4 \pi v \Delta T(T),
$$

где $\Delta T$ - амплитуда колебаний температуры нитей с частотой $2 v$, $Q / 4 \pi v$ - количество тепла, затраченное на нагрев образца за $1 / 2$ периода тепловой волны.

Таким образом, при постоянной мощности нагревателя для определения температурной зависимости теплоемкости надо измерить температурную зависимость $\Delta T$. В качестве термометра в данном случае использовался сам сверхпроводящий переход, поскольку он существует 


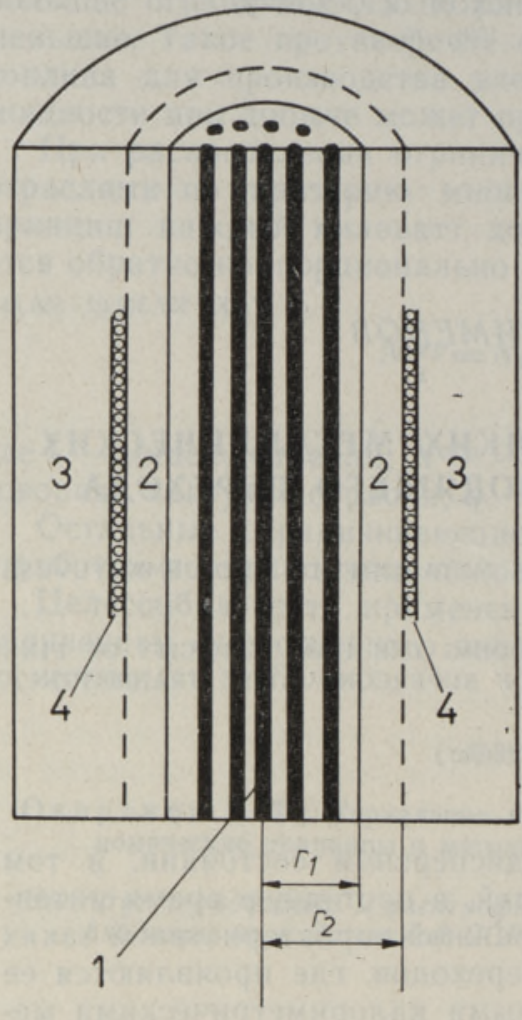

Рис. 1. Схематическое изображение образца: 1 - асбестовая матрица с каналами, заполненными металлом; 2 и 3 - эпоксидная смола; 4 - нагреватель; $r_{1} \cong 0,05 \cdot 10^{-3} \quad M, r_{2} \cong$ $\cong 0,15 \cdot 10^{-3} \mathrm{M}$.

на значительном температурном интервале («размытие» сверхпроводящего перехода за счет флуктуаций составляет порядка 2 градусов для нитей диаметром $\left.20 \AA\left[{ }^{3}\right]\right)$. Для вычисления $\Delta T$ необходимо знать $R$ - сопротивление нитей в области сверхпроводящего перехода и $U_{2 v}$ - переменный сигнал частоты $2 v$, которые связаны с $\Delta T$ формулами

$$
\frac{1}{\Delta T}=\frac{\partial R}{\partial T} \cdot \frac{1}{\Delta R}, \quad \Delta R=U_{2 v} / I_{0},
$$

где $I_{0}$ - постоянный ток, пропускаемый через образец. И хотя определенная таким образом теплосмкость относится не только к нитям, но и к матрице, помешать качеству измерений это не может, так как у матрицы никаких особенностей в этой области температур нет.

В целях уменьшения затухания тепловой волны на пути нагреватель-тонкие нити измерения проводилйсь на низкой частоте $\sim 10 \Gamma ц$. Корректность метода проверялась измерением теплоемкости на частотах $10-50 Г ц$ и расчетом средней абсолютной величины теплоемкости всего гсследуемого образца. Для оценки последней величины рассчитывалось затухание теплового потока на пути нагреватель-матрица с тонкими нитями (см. рис. 1). При расчете образец считался бесконечным цилиндром, а нагреватель - сосредоточенным на границах областей 2 и 3. Затухание тепловой волны на тонких нитях вследствие их большой температуропроводности (по сравнению с температуропроводностью асбестовой матрицы) не учитывалось. В принятых приближениях исходные уравнения имеют следующий вид: 


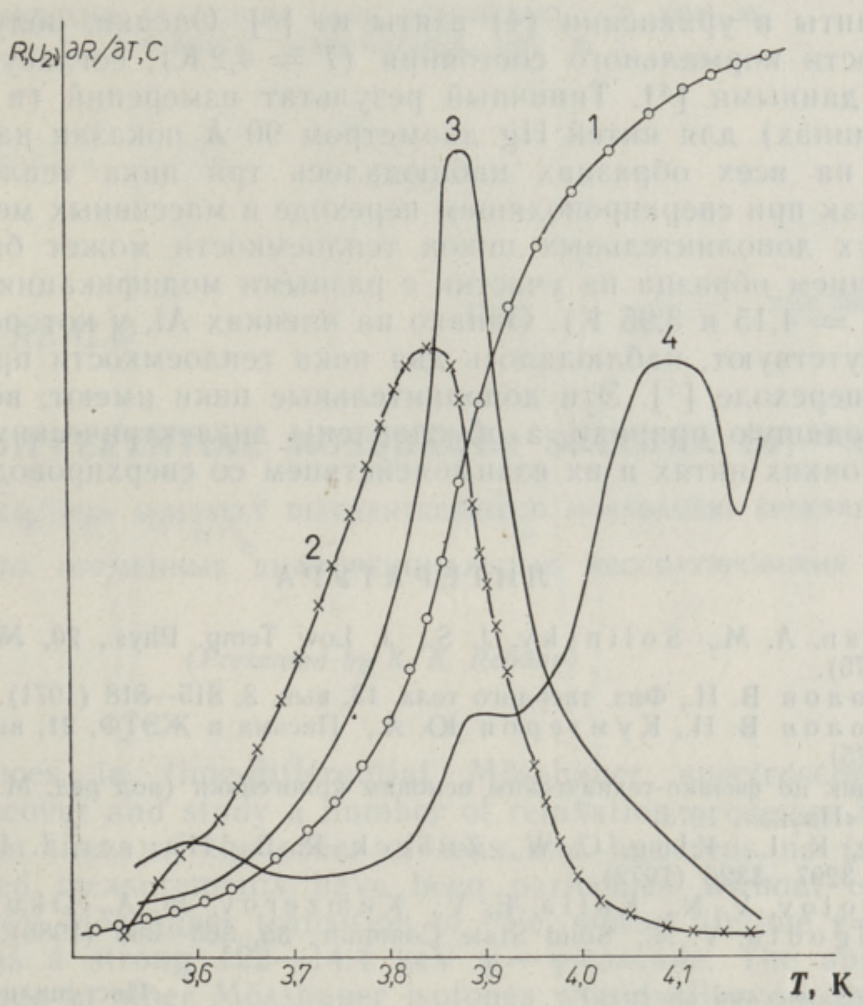

Рис. 2. Результат измерения теплоемкости нитей $\mathrm{Hg}$ : $i-R(T), 2-U_{2 v}, 3-\partial R / \partial T, 4-C(T)$.

$$
c_{j} \mathrm{Q}_{j} \frac{\partial T_{j}}{\partial \tau}=\frac{1}{r} \frac{\partial}{\partial r}\left(\lambda_{j} r \frac{\partial T_{j}}{\partial r}\right), \quad j=1,2,3
$$

где $c_{j}, \varrho_{j}, \lambda_{j}$ - теплоемкость, плотность и теплопроводность соответственно ооластей $j$. Граничные условия:

$$
\begin{aligned}
& T_{r_{r \rightarrow \infty}} \rightarrow \text { orp, } \quad \frac{\partial T_{1}}{\partial r_{\mid r=0}}=0 \\
& T_{j_{\mid r=r_{f-1}}}=\left.T_{j-1}\right|_{\mid r=r_{l-1}}, \lambda_{j} \frac{\partial T_{j}}{\partial r_{\mid r=r_{f-1}}}=\lambda_{j-1} \frac{\partial T_{j-1}}{\partial r_{\mid r=r_{l-1}}}+q_{j}, q_{j}=\left\{\begin{array}{c}
q_{\text {н }} \text { если } j=3, \\
0, \text { если } j=2,
\end{array}\right.
\end{aligned}
$$

$q_{\mathrm{H}}=q_{0} \exp (i \omega \tau), \omega=4 \pi v, q_{0}-$ амплитуда теплового потока от нагре вателя.

Решение ищется в виде $T_{j}=T_{\omega j} \exp (i \omega \tau)$. Искомое распределение теплового потока в области 1 имеет вид

$$
q(r) / q_{0}=|Z| \cdot\left|I_{1}\left(\varphi_{1} r\right)\right|,
$$

где $I_{1}\left(\varphi_{1} r\right)$ - функция Бесселя мнимого аргумента, $Z-$ дробно-линейная функция от функций Бесселя мнимого аргумента, $\varphi_{1}=\sqrt{i} \sqrt{4 \pi v / a_{1}}$. $a_{1}=\lambda_{1} / c_{1} \varrho_{1}$. 
Константы в уравнении (4) взяты из [ $\left.{ }^{4}\right]$. Оценки, полученные для теплоемкости нормального состояния $(T=4,2 \mathrm{~K})$, согласуются с табличными данными $\left[{ }^{4}\right]$. Типичный результат измерений (в относительных величинах) для нитей $\mathrm{Hg}$ диаметром $90 \AA \AA$ показан на рис. 2.

Итак, на всех образцах наблюдалось три пика теплоемкости, а не один, как при сверхпроводящем переходе в массивных металлах. Наличие двух дополнительных пиков теплоемкости может быть связано с расслоением образца на участки с разными модификациями $\mathrm{Hg}(\alpha$ н $\beta \mathrm{Hg}$ с $T_{k}=4,15$ и $\left.3,95 \mathrm{~K}\right)$. Однако на пленках $\mathrm{Al}$, у которого модификации отсутствуют, наблюдалось два пика теплоемкости при сверхпроводящем переходе [ $\left.{ }^{5}\right]$. Эти дополнительные пики имеют, возможно, не сверхпроводящую природу, а обусловлены диэлектрическими флуктуациями в тонких нитях и их взаимодействием со сверхпроводящим переходом $\left[{ }^{6}\right]$.

\section{ЛИТ ЕРАТ У Р А}

1. Goldman, A. M., Solinsky, J. S., J. Low Temp. Phys., 20, № 3/4, 339-363 (1975).

2. Богом олов В. Н., Физ. твердого тела, 13, вып. 3, 815-818 (1971).

3. Богомолов В. Н., К у мзеров Ю. А., Письма в ЖЭТФ, 21, вып. 7, 434-438 (1975).

4. Справочник по физико-техническим основам криогеники (под ред. М. П. Малкова), М., «Наука», 1973.

5. Greene, K. L., King, C. W., Zubeck, R. B., Hauser, I. I., Phys. Rev., B6, 3297-3326 (1972).

6. Bogomolov, V. N., Kolla, E. V., Kumzerov, Ju. A., Okuneva, N. M., Prigodin, V. N., Solid State Commun, 35, 363-366 (1980).

Физико-технический институт и.м. А. Ф. Ноффе

Академии наук СССР
Поступила в редакцию 4/XII 1980 